\title{
Estimating mixing processes of sources contributing to baseflow in Alpine headwater catchments
}

\section{Other Conference Item}

Author(s):

Floriancic, Marius (D); Roques, Clément; Jimenez-Martinez, Joaquin (D)

Publication date:

2020-05

Permanent link:

https://doi.org/10.3929/ethz-b-000463221

Rights / license:

Creative Commons Attribution 4.0 International

Originally published in:

EGUsphere, https://doi.org/10.5194/egusphere-egu2020-1721 
EGU2020-1721

https://doi.org/10.5194/egusphere-egu2020-1721

EGU General Assembly 2020

(c) Author(s) 2021. This work is distributed under

the Creative Commons Attribution 4.0 License.

\title{
Estimating mixing processes of sources contributing to baseflow in Alpine headwater catchments
}

\author{
Marius G. Floriancic ${ }^{1,2}$, Clément Roques ${ }^{3}$, and Joaquin Jimenez-Martinez $z^{2,4}$ \\ ${ }^{1}$ ETH Zürich, Institute of Terrestrial Ecosystems, Zürich, Switzerland (floriancic@ifu.baug.ethz.ch) \\ ${ }^{2}$ ETH Zürich, Insitute of Environemntal Engineering, Zürich, Switzerland \\ ${ }^{3}$ ETH Zürich, Geological Institute, Zürich, Switzerland \\ ${ }^{4}$ EAWAG, Department of Water Resources and Drinking Water, Dübendorf, Switzerland
}

Baseflow is fed by groundwater to a large fraction. Estimating water quantity and quality from groundwater stores is essential for water management. However, there are few datasets available that contain detailed water chemistry analysis on high spatial resolution across multiple headwater catchments in (high) Alpine environments. This information is essential to analyze mixing processes on catchment scale from distinct landscape features.

We use two data sets: i) water chemistry analysis snapshot sampling campaigns in 7 headwater streams during low $\square$ flow periods across Switzerland, and ii) a detailed chemical screening (every $25 \mathrm{~m}$ ) in one selected catchment during baseflow, including electric conductivity and temperature. Major ions, stable isotopes, TOC, DOC, trace elements were analyzed for some of the samples (> 80). These data reveal the chemical fingerprint of the contributing groundwater sources. The chemical composition of these contributing sources to baseflow is largely influenced by weathering products depended on lithology and geomorphology. Using maximum likelihood calculations, we define the ion composition and the isotopic signature of the potential major endmembers (up to three), based on the mixed samples along the main stem.

The proposed methodology allows to i) reduce uncertainty of the endmembers, and ii) quantify the relative contribution of different lithology and geomorphological features to streamflow and shows iii) which spatial scale of input information is needed to analyze mixing processes from various groundwater sources. Our results show how the contribution of different lithologies, along with topography and geomorphological features, varies spatially throughout Alpine headwater catchments. 